\title{
Confirmatory Analysis of QUARTZ Study Results: Survival Prolongation after Whole-brain Radiotherapy
}

\author{
CARSTEN NIEDER ${ }^{1,2}$, ASTRID DALHAUG $^{1}$ and ADAM PAWINSKI ${ }^{1}$ \\ ${ }^{1}$ Department of Oncology and Palliative Medicine, Nordland Hospital, Bodø, Norway; \\ ${ }^{2}$ Department of Clinical Medicine, Faculty of Health Sciences, UiT - The Arctic \\ University of Norway, Tromsø, Norway
}

Correspondence to: Dr. Carsten Nieder, Department of Oncology and Palliative Medicine, Nordland Hospital, 8092 Bodø, Norway, Tel: +47 7557 8449, Fax: +47 75 53 4975, e-mail: carsten.nieder@nlsh.no

Key Words: Palliative radiotherapy, whole-brain radiotherapy, supportive care, brain metastases, prognostic factors.

Running title: Whole-brain radiotherapy or best supportive care Clinical study, submitted 02.01.2020 
Abstract. Background/Aim: The aim of this study was to analyze the survival of patients with brain metastases treated with best supportive care or additional whole-brain radiotherapy (WBRT), in order to confirm results from the prospective randomized QUARTZ study, which suggested prolonged survival after WBRT (5 fractions of 4 Gy) if favorable prognostic factors were present (age younger than 60 years, graded prognostic assessment score 2.5-3 points). Patients and Methods: We performed a retrospective single institution analysis of 76 patients with favorable prognosis. In contrast to the QUARTZ trial, inclusion was not limited to patients with non-small cell lung cancer (NSCLC). Furthermore, a cohort treated with higher total doses of WBRT was included (10 fractions of $3 \mathrm{~Gy}$ ). Results: All patients were younger than 60 years or had a graded prognostic assessment score of 2.5-3. The median survival was significantly shorter after best supportive care (1.2 months; 3.2 months after WBRT with 5 fractions of 4 Gy and 3.9 months after 10 fractions of $3 \mathrm{~Gy}$ ). Also, in multivariate analyses, survival was significantly better after WBRT. Further favorable prognostic factors included better performance status, no or limited extracranial metastases and primary tumor other than gastrointestinal. Conclusion: In line with the QUARTZ trial results, WBRT prolonged survival in patients with favorable prognostic features. 
In patients with brain metastases from extracranial primary tumors, such as lung or breast cancer, current treatment options include surgical resection and stereotactic radiotherapy, as well as whole-brain radiotherapy (WBRT) and best supportive care (BSC) without metastases-directed approaches (1-3). Patient selection is not always trivial, especially when it comes to the decision to withhold active, metastases-directed approaches (4-6). The prospective randomized multicenter QUARTZ trial was a pragmatic trial performed between 2007 and 2014 (7). The protocol required uncertainty in the clinicians' or patients' minds about the potential benefit of WBRT and used a noninferiority design. All patients had non-small cell lung cancer (NSCLC) and were offered BSC including dexamethasone, which a significant majority received. In the WBRT arm, treatment consisted of 5 fractions of 4 Gy each. The primary outcome measure was quality-adjusted life-years (QALYs). Median age was 66 years (range=38-85). The authors concluded that there was no significant difference in QALYs between the two treatment arms (mean= 46.4 QALY days for the WBRT arm versus 41.7 QALY days for WBRT and BSC, respectively). There was also no significant difference observed in overall survival (hazard ratio $=1.06,95 \%$ confidence interval $=0.90-1.26$ ) between the two groups. In the WBRT arm, median survival was 9.2 weeks. However, WBRT prolonged survival in patients younger than 60 years of age (hazard ratio $=1.48,95 \%$ confidence interval $=1.01-2.16)$ and those with graded prognostic assessment (GPA) score of 2.5-3 points (hazard ratio $=1.65,95 \%$ confidence interval $=1.04-2.60$ ). The GPA score is a widely used 4-tiered prognostic model based on different baseline parameters, which differ by primary diagnosis, e.g. lung cancer, breast cancer, malignant melanoma and kidney cancer (8). Given that many patients with brain metastases have primary tumors other than NSCLC, we designed a retrospective study of WBRT versus BSC that included all patients irrespective of primary tumor, if they had the same favorable prognostic 
features that were associated with better survival after WBRT in the QUARTZ trial, i.e. age younger than 60 years or diagnosis-specific GPA 2.5-3 points. Furthermore, we included an additional group of patients treated with WBRT who received a higher total dose than in the QUARTZ trial (10 fractions of 3 Gy).

\section{Material and Methods}

Patients and treatment

A retrospective study of all patients with parenchymal brain metastases from histologically verified extracranial primary tumors treated with WBRT ( 5 fractions of 4 Gy or 10 fractions of 3 Gy, no boost) or BSC at our hospital was performed. The patients were treated between January 01, 2007 and December 31, 2018 and identified from a continuously updated database $(9,10)$. None of the patients had received previous treatment for brain metastases (neither prophylactic cranial irradiation). After WBRT, further systemic and local treatment was individualized. The choice between the two WBRT regimens was at the discretion of the radiation oncologist. BSC was typically pursued if recommended by the multidisciplinary tumor board and agreed by the patients and caregivers. Factors such as old age, poor Karnofsky performance score (KPS) and extensive metastatic spread were common reasons to recommend BSC. The diagnosis-specific GPA was assigned as originally described by Sperduto et al. (8). The maximum point sum was 4 , minimum 0 . A point sum of 2.5-3 indicates a relatively good prognosis. Inclusion was limited to patients with 2.5-3 points or age younger than 60 years.

\section{Statistical methods}

Overall survival (time to death) from imaging diagnosis of brain metastases was calculated employing the Kaplan-Meier method, and different groups were compared 
using the log-rank test (SPSS 25, IBM Corp., Armonk, NY, USA). Only two patients were censored. Date of death was known in all other patients. A Cox forward conditional regression model was employed for multivariate analysis. The chi-square test was used to compare differences in baseline characteristics between the patient groups. Statistical significance was defined as $p \leq 0.05$ throughout this study.

\section{Results}

Patient characteristics

We identified 76 patients from the database. Thirty-two (42\%) had NSCLC. The median age was 55.5 years. Twenty patients (26\%) were included because of their favorable diagnosis-specific GPA score, meaning that age younger than 60 years was the prevailing reason for inclusion. Further patient characteristics are shown in Table I.

\section{Treatment}

Fourteen patients (18\%) received BSC, 9 (12\%) WBRT with the 5-fraction regimen and $53(70 \%)$ with the 10 -fraction regimen. In the latter group, one patient did not complete all 10 fractions of WBRT.

\section{Survival}

The median overall survival of the BSC group was 1.2 months. As shown in Figure 1, WBRT was associated with significantly better survival. The difference between the 5and 10 -fraction regimens was not statistically significant. Beyond WBRT, other factors were associated with better survival: female gender $(p=0.057)$, non-gastrointestinal primary tumor $(p=0.025)$, no extracranial metastases or to one organ only $(p=0.009)$, 
better KPS $(p=0.0001), 1-3$ brain metastases $(p=0.027)$, better diagnosis-specific GPA $(p=0.001)$.

Importantly, patients in the 10-fraction WBRT group had significantly better KPS (Table I). However, they also had a significantly larger number of brain metastases. There was also a difference regarding median age (BSC: 57 years, WBRT 5 fractions: 53 years, WBRT 10 fractions: 55 years, $p=0.048$ ). Two different multivariate analyses of overall survival were performed to adjust for differences in baseline prognostic parameters. One included only the diagnosis-specific GPA as a surrogate of confounding prognostic imbalance and showed that both GPA $(p=0.002)$ and WBRT $(p=0.0001)$ influenced survival. The other one included all individual prognostic factors rather than GPA and showed that WBRT $(p=0.008), \operatorname{KPS}(p=0.0001)$, non-gastrointestinal cancer $(p=0.03)$ and absence of extracranial metastases or involvement of maximum one organ $(p=0.02)$ influenced survival. Female gender and number of brain metastases lost their significance in this model.

\section{Discussion}

The large randomized QUARTZ trial has previously shown that WBRT (5 fractions of 4 Gy) prolonged survival in patients with NSCLC who were younger than 60 years of age (hazard ratio $=1.48$ ) and those with GPA score of $2.5-3$ points (hazard ratio= 1.65 ). The subgroup with GPA score of 3.5-4 points was too small for meaningful analyses. Since many patients with brain metastases have primary tumors other than NSCLC additional evidence from mixed cohorts is required. Moreover, WBRT with higher total dose (10 fractions of 3 Gy) may in principle result in even better survival than WBRT with lower total dose. These considerations prompted us to perform the present retrospective study, 
which compares three different strategies: BSC, 5-fraction WBRT and 10-fraction WBRT in patients with favorable prognostic characteristics, as defined from the results of the QUARTZ trial.

Limitations of the present study include the limited number of patients, statistical power of subgroup analyses, and retrospective design. Fewer patients than anticipated were managed with BSC and 5-fraction WBRT. Nevertheless, the survival difference between these two groups, which persisted in the multivariate models, is in line with the findings from the QUARTZ trial. Interestingly, 10-fraction WBRT was not significantly better than 5-fraction WBRT. On the other hand, all long-term survivors belonged to the group with 10-fraction WBRT. In the absence of randomization, this finding may still be caused by selection bias and the fact that the WBRT regimens were assigned according to physicians' choice. In order to increase the statistical power, multivariate analyses were stratified by BSC or any WBRT, rather than three different strata. As a result of the patient selection criteria mentioned above, the present cohort was younger than generally observed in the literature (11-16).

Primary WBRT has recently become a rather controversial approach, especially in patients with better prognosis and/or limited number of brain metastases $(17,18)$. Advanced WBRT techniques with hippocampal sparing and dose escalation on visible brain metastases are under study and may eventually increase the acceptance of WBRT (19). On the other hand, focal stereotactic radiotherapy, which results in superior local control than conventional 10 -fraction WBRT, will continue to play an important role. It is likely that improved prognostic models will impact on patient selection, both regarding the decision towards BSC in patients with poor prognostic features and the decision to 
recommend effective local treatment in other patients (20-23). The original diagnosisspecific GPA as used in the QUARTZ trial will soon be replaced by its new and refined variants $(24,25)$.

\section{Conclusion}

In line with the QUARTZ trial results, WBRT prolonged survival in patients with favorable prognostic features, defined as age younger than 60 years or diagnosis-specific GPA score 2.5-3 points.

\section{Conflicts of Interest}

The Authors declare that they have no competing interests.

\section{Acknowledgements}

None. No funding to disclose.

\section{Authors' Contributions}

CN participated in the design of the study and performed the statistical analysis. AD and AP collected patient data. CN, and AD conceived the study and drafted the article. All Authors read and approved the final article. 


\section{References}

1 Soffietti R, Kocher M, Abacioglu UM, Villa S, Fauchon F, Baumert BG, Fariselli L, Tzuk-Shina T, Kortmann RD, Carrie C, Ben Hassel M, Kouri M, Valeinis E, van den Berge D, Mueller RP, Tridello G, Collette L and Bottomley A: A European Organisation for Research and Treatment of Cancer phase III trial of adjuvant whole-brain radiotherapy versus observation in patients with one to three brain metastases from solid tumors after surgical resection or radiosurgery: quality-oflife results. J Clin Oncol 31: 65-72, 2013. PMID: 23213105. DOI: $10.1200 / J C O .2011 .41 .0639$

2 Bilger A, Bretzinger E, Fennell J, Nieder C, Lorenz H, Oehlke O, Grosu AL, Specht HM and Combs SE: Local control and possibility of tailored salvage after hypofractionated stereotactic radiotherapy of the cavity after brain metastases resection. Cancer Med 7: 2350-2359, 2018. PMID: 29745035. DOI: $10.1002 /$ cam4.1486

3 Ampil F, Ellika S, Nanda A and Vora M: Long-term survival after stereotactic radiosurgery of brain metastases: A case series with 10-year follow-up. Anticancer Res 37: 5113-5115, 2017. PMID: 28870942. DOI: 10.21873/anticanres.11930

4 Soffietti R, Abacioglu U, Baumert B, Combs SE, Kinhult S, Kros JM, Marosi C, Metellus P, Radbruch A, Villa Freixa SS, Brada M, Carapella CM, Preusser M, Le Rhun E, Rudà R, Tonn JC, Weber DC and Weller M: Diagnosis and treatment of brain metastases from solid tumors: guidelines from the European Association of Neuro-Oncology (EANO). Neuro Oncol 19: 162-174, 2017. PMID: 28391295. DOI: 10.1093/neuonc/now241

5 Nieder C, Guckenberger M, Gaspar LE, Rusthoven CG, De Ruysscher D, Sahgal A, Nguyen T, Grosu AL and Mehta MP: Management of patients with brain 
metastases from non-small cell lung cancer and adverse prognostic features: multi-national radiation treatment recommendations are heterogeneous. Radiat Oncol 14:33, 2019. PMID: 30770745. DOI: 10.1186/s13014-019-1237-9

6 Nieder C, Norum J, Hintz M and Grosu AL: Short survival time after palliative whole brain radiotherapy: Can we predict potential overtreatment by use of a nomogram? J Cancer 8: 1525-1529, 2017. PMID: 28775771. DOI: 10.7150/jca.18600

7 Mulvenna P, Nankivell M, Barton R, Faivre-Finn C, Wilson P, McColl E, Moore B, Brisbane I, Ardron D, Holt T, Morgan S, Lee C, Waite K, Bayman N, Pugh C, Sydes B, Stephens R, Parmar MK and Langley RE: Dexamethasone and supportive care with or without whole brain radiotherapy in treating patients with non-small cell lung cancer with brain metastases unsuitable for resection or stereotactic radiotherapy (QUARTZ): results from a phase 3, non-inferiority, randomised trial. Lancet 388: 2004-2014, 2016. PMID: 27604504. DOI: 10.1016/S0140-6736(16)30825-X

8 Sperduto PW, Kased N, Roberge D, Xu Z, Shanley R, Luo X, Sneed PK, Chao ST, Weil RJ, Suh J, Bhatt A, Jensen AW, Brown PD, Shih HA, Kirkpatrick J, Gaspar LE, Fiveash JB, Chiang V, Knisely JP, Sperduto CM, Lin N and Mehta M: Summary report on the graded prognostic assessment: an accurate and facile diagnosisspecific tool to estimate survival for patients with brain metastases. J Clin Oncol 30: 419-425, 2012. PMID: 22203767. DOI: 10.1200/JCO.2011.38.0527

9 Nieder C, Hintz M, Oehlke O, Bilger A and Grosu AL: The TNM 8 M1b and M1c classification for non-small cell lung cancer in a cohort of patients with brain metastases. Clin TransI Oncol 19:1141-1146, 2017. PMID: 28357633. DOI: doi: $10.1007 / \mathrm{s} 12094-017-1651-0$

10 Nieder C, Dalhaug A and Pawinski A: Serum lactate dehydrogenase contributes to prognostic assessment in patients with oligometastatic cancer and brain 
involvement. In Vivo 33: 229-232, 2019. PMID: 30587628. DOI: 10.21873/invivo.11464

11 Jeene PM, de Vries KC, van Nes JGH, Kwakman JJM, Wester G, Rozema T, Braam PM, Zindler JD, Koper P, Nuyttens JJ, Vos-Westerman HA, Schmeets I, Niël CGHJ, Hutschemaekers S, van der Linden YM, Verhoeff JJC and Stalpers LJA: Survival after whole brain radiotherapy for brain metastases from lung cancer and breast cancer is poor in 6325 Dutch patients treated between 2000 and 2014 . Acta Oncol 57: 637-643, 2018. PMID: 29276848. DOI: 10.1080/0284186X.2017.1418534

12 Miyazawa K, Shikama N, Okazaki S, Koyama T, Takahashi T and Kato S: Predicting prognosis of short survival time after palliative whole-brain radiotherapy. J Radiat Res 59: 43-49, 2018. PMID: 29069502. DOI: 10.1093/jrr/rrx058

13 Rades D, Dziggel L and Schild SE: A specific survival score for patients receiving local therapy for single brain metastasis from a gynecological malignancy. In Vivo 32: 825-828, 2018. PMID: 29936465. DOI: 10.21873/invivo.11314

14 Rades D, Blanck O, Khoa MT, VAN Thai P, Hung NQ, Dziggel L and Schild SE: Validation of a survival score for patients receiving radiosurgery or fractionated stereotactic radiotherapy for 1 to 3 brain metastases. In Vivo 32: 381-384, 2018. PMID: 29475924. DOI: 10.21873/invivo.11249

15 Saruwatari K, Ikeda T, Saeki S, Shingu N, Imamura K, Komatu T, Ushijima S, Maruyama H, Kashiwabara K, Tomita Y, Ichiyasu H, Fujii K and Sakagami T: Upfront cranial radiotherapy followed by erlotinib positively affects clinical outcomes of epidermal growth factor receptor-mutant non-small cell lung cancer with brain metastases. Anticancer Res 39: 923-931, 2019. PMID: 30711977. DOI: 10.21873/anticanres. 13195 
16 Hansen HC, Janssen S, Thieme C, Perlov A, Schild SE and Rades D: Whole-brain radiotherapy (WBRT) for brain metastases: Does the interval between imaging and treatment matter? Anticancer Res 38: 6835-6840, 2018. PMID: 30504398. DOI: 10.21873/anticanres. 13057

17 Brown PD, Ahluwalia MS, Khan OH, Asher AL, Wefel JS and Gondi V: Wholebrain radiotherapy for brain metastases: Evolution or revolution? J Clin Oncol 36 . 483-491, 2018. PMID: 29272161. DOI: 10.1200/JCO.2017.75.9589

18 Andratschke N, Kraft J, Nieder C, Tay R, Califano R, Soffietti R and Guckenberger M: Optimal management of brain metastases in oncogenic-driven non-small cell lung cancer (NSCLC). Lung Cancer 129: 63-71, 2019. PMID: 30797493. DOI: 10.1016/j.lungcan.2018.12.009

19 Oehlke O, Wucherpfennig D, Fels F, Frings L, Egger K, Weyerbrock A, Prokic V, Nieder C and Grosu AL: Whole brain irradiation with hippocampal sparing and dose escalation on multiple brain metastases: Local tumour control and survival. Strahlenther Onkol 191: 461-469, 2015. PMID: 25592907. DOI: 10.1007/s00066014-0808-9

20 Nieder C, Marienhagen K, Dalhaug A, Aandahl G, Haukland E and Pawinski A: Prognostic models predicting survival of patients with brain metastases: integration of lactate dehydrogenase, albumin and extracranial organ involvement. Clin Oncol (R Coll Radiol) 26: 447-452, 2014. PMID: 24702741. DOI: 10.1016/j.clon.2014.03.006

21 Zindler JD, Jochems A, Lagerwaard FJ, Beumer R, Troost EGC, Eekers DBP, Compter I, van der Toorn PP, Essers M, Oei B, Hurkmans CW, Bruynzeel AME, Bosmans G, Swinnen A, Leijenaar RTH and Lambin P: Individualized early death and long-term survival prediction after stereotactic radiosurgery for brain 
metastases of non-small cell lung cancer: Two externally validated nomograms. Radiother Oncol 123: 189-194, 2017. PMID: 28237400. DOI: 10.1016/j.radonc.2017.02.006

22 Nieder C, Dalhaug A and Pawinski A: External validation of the LabBM score in patients with brain metastases. J Clin Med Res 11: 321-325, 2019. PMID: 31019625. DOI: 10.14740/jocmr3746

23 Lewitzki V, Klement RJ, Hess S, Kosmala R, Nieder C and Flentje M: External validation of a prognostic score predicting overall survival for patients with brain metastases based on extracranial factors. Clin Transl Radiat Oncol 16: 15-20, 2019. PMID: 30906886. DOI: 10.1016/j.ctro.2019.02.005

24 Sperduto PW, Deegan BJ, Li J, Jethwa KR, Brown PD, Lockney N, Beal K, Rana NG, Attia A, Tseng CL, Sahgal A, Shanley R, Sperduto WA, Lou E, Zahra A, Buatti JM, Yu JB, Chiang V, Molitoris JK, Masucci L, Roberge D, Shi DD, Shih HA, Olson A, Kirkpatrick JP, Braunstein S, Sneed P and Mehta MP: Estimating survival for renal cell carcinoma patients with brain metastases: an update of the Renal Graded Prognostic Assessment tool. Neuro Oncol 20: 1652-1660, 2018. PMID: 30418657. DOI: 10.1093/neuonc/noy099

25 Sperduto PW, Jiang W, Brown PD, Braunstein S, Sneed P, Wattson DA, Shih HA, Bangdiwala A, Shanley R, Lockney NA, Beal K, Lou E, Amatruda T, Sperduto WA, Kirkpatrick JP, Yeh N, Gaspar LE, Molitoris JK, Masucci L, Roberge D, Yu J, Chiang $\mathrm{V}$ and Mehta $\mathrm{M}$ : Estimating survival in melanoma patients with brain metastases: An update of the graded prognostic assessment for melanoma using molecular markers (Melanoma-molGPA). Int J Radiat Oncol Biol Phys 99: 812816, 2017. PMID: 29063850. DOI: 10.1016/j.jijrobp.2017.06.2454 


\section{Figure Legend}

Figure 1. Actuarial overall survival after BSC (RT 0, median 1.2 months), 5 fractions of WBRT (RT 20, median 3.2 months) and 10 fractions of WBRT (RT 30, median 3.9 months); log-rank test $p$-values: 0.05 (BSC versus 5 fractions), 0.0001 (BSC versus 10 fractions) and 0.18 (5 versus 10 fractions). 


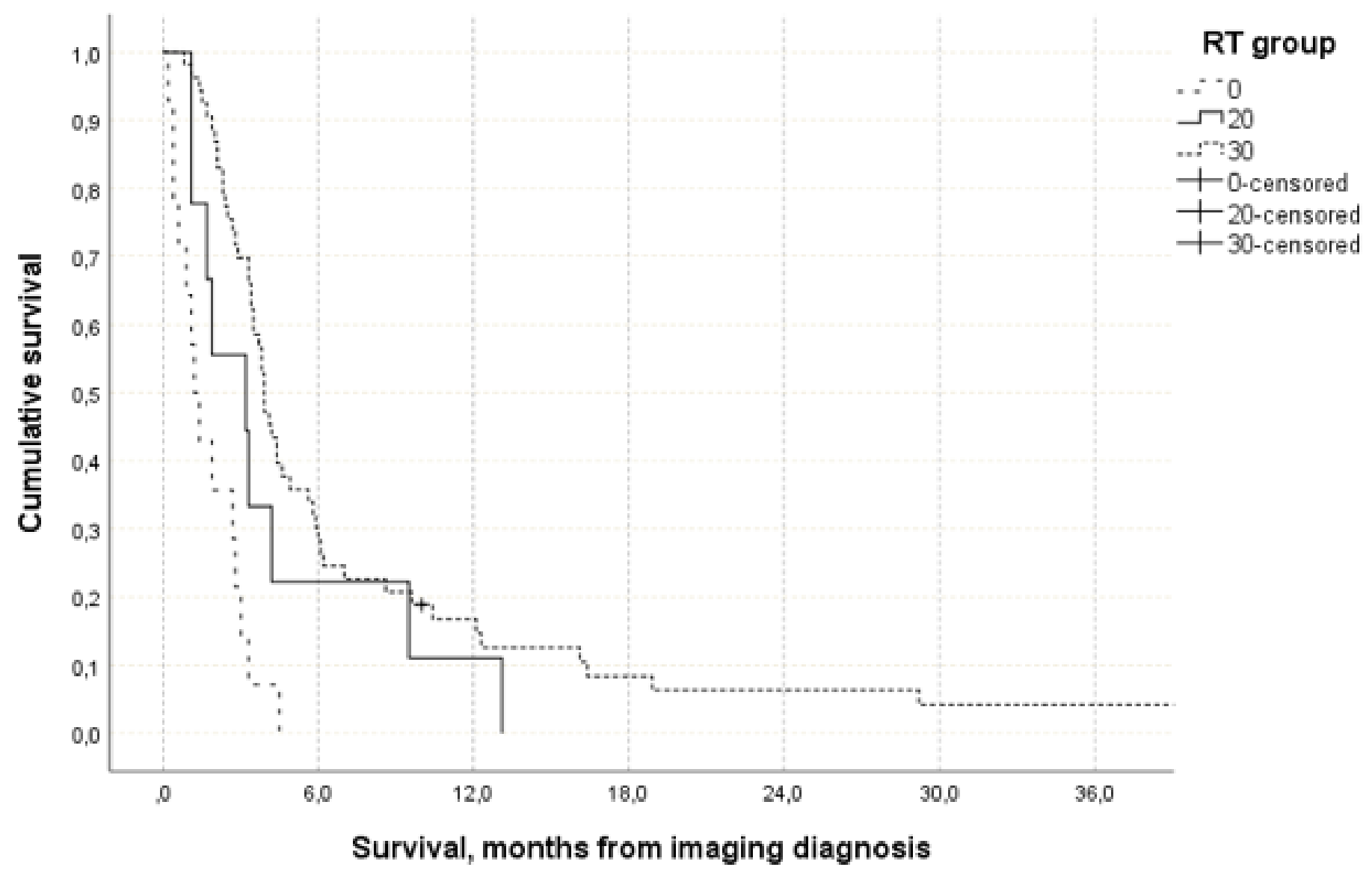


Table I. Patient characteristics.

\begin{tabular}{|c|c|c|c|c|}
\hline Baseline parameter & BSC & WBRT 5 fractions & WBRT 10 fractions & $\begin{array}{l}\text { Significant differences } \\
\text { between the groups }\end{array}$ \\
\hline Non-small cell lung cancer & 5 & 5 & 22 & \\
\hline Small cell lung cancer & 1 & 1 & 4 & \\
\hline Breast cancer & 0 & 0 & 9 & \\
\hline Malignant melanoma & 2 & 2 & 6 & \\
\hline Kidney cancer & 2 & 0 & 5 & \\
\hline Gastrointestinal cancer & 3 & 1 & 6 & \\
\hline Other primary & 1 & 0 & 1 & \\
\hline Synchronous brain metastases ${ }^{*}$ & 2 & 2 & 10 & \\
\hline No extracranial metastases & 2 & 1 & 11 & \\
\hline Extracranial metastases, one organ, e.g. bones & 1 & 4 & 11 & \\
\hline Extracranial metastases, at least two organs & 11 & 4 & 31 & \\
\hline Controlled primary tumor & 9 & 5 & 34 & \\
\hline Female gender & 5 & 4 & 30 & \\
\hline Male gender & 9 & 5 & 23 & \\
\hline $1-3$ brain metastases & 11 & 5 & 20 & \\
\hline More than 3 brain metastases ${ }^{\star *}$ & 3 & 4 & 33 & $p=0.021$ \\
\hline $\mathrm{KPS}>70$ & 0 & 1 & 17 & \\
\hline KPS 70 & 4 & 3 & 26 & \\
\hline KPS $<70$ & 10 & 5 & 10 & $p=0.001$ \\
\hline Poor diagnosis-specific GPA, 0-1 & 7 & 5 & 24 & \\
\hline Intermediate diagnosis-specific GPA, 1.5-2 & 3 & 4 & 11 & \\
\hline
\end{tabular}


BSC: Best supportive care; WBRT: whole-brain radiotherapy; KPS: Karnofsky performance score; GPA: graded prognostic assessment.

${ }^{*}$ Median time interval from first cancer diagnosis $9.5,6.0$ and 9.0 months, $p=0.65$.

** Median number of brain metastases in each group: 1.5, 3.0 and 5.0, $p=0.05$.

***Undefined GPA in two cases. Median GPA in each group: 1.0, 1.0 and 1.5, $p=0.097$. 